\title{
Conversion Rate to Resectability in Colorectal Cancer Liver Metastases: Need for Criteria Adapted to Current Therapy.
}

\author{
Timofeiov $\mathbf{S}^{1,3}$, Marinca $\mathbf{M}^{1,5}$, Camelia Bar ${ }^{7}$, Mihaela Elena Breabăn², Drug $\mathbf{V}^{1,6}$, Scripcariu $\mathbf{V}^{1,4}$ \\ ${ }^{1}$ University of Medicine and Pharmacy „Gr.T. Popa”, Faculty of Medicine, lasi, Romania \\ 2University "Alexandru loan Cuza”, Faculty of Computer Science, lasi, Romania \\ ${ }^{3}$ Third Surgical Clinic of "Sf. Spiridon" Hospital, lasi, Romania \\ ${ }^{4}$ First Surgical Oncology Unit, Regional Institute of Oncology laşi, Romania \\ ${ }^{5}$ Oncology Unit, Regional Institute of Oncology laşi, Romania \\ ${ }^{6}$ Instiute of Gastroenetrology and Hepatology "Sf. Spiridon" Hospital lasi, Romania \\ ${ }^{7}$ Medical Imaging Center "Arcadia", lasi, Romania
}

\begin{abstract}
Background: Therapeutic strategy for patients with colorectal cancer liver metastases (CRLM) is based on good monitoring and correct assignment to classes of liver resectability based on imaging criteria, taking into account the surgical risk.

Objective: To identify the post-treatment time frame for confirming resectability (conversion to resecability) or permanent unresectability.

Methods: The study is a prospective analysis based on a Scientific Protocol (Surveillance of patients with colorectal cancer liver metastases) used in the Ist Surgical Oncology Unit, Regional Institute of Oncology laşi, Romania. Surgical treatment, oncologic treatment, response to therapy, postoperative surgical complications, were assessed at 3, 6 and 9 months after start of the study.

Results: In the interval July 2012 - January 2014, 106 patients were diagnosed with CRLM. According to the classes of liver resectability the patients were divided into four groups: group I (clear resectability), group II (possibly resectability), group III (susceptible resectability), group IV (unresectable metastases). Relevant for the study were only groups II and III. Thus, in group II patients the rate of conversion to resectability was $23.07 \%$ and in group III patients $26.66 \%$. These results were obtained after 3,6 and 9 months of therapy, respectively.

Conclusions: Rigorous surveillance of patients with CRLM according to a well-established scientific protocol, and their assignment to liver resectability classes represent the first step ofthe oncosurgical therapeutic strategy. An improvement in the rate of conversion to resectability could be achieved through regular assessment of treatment response based on international criteria that should include besides the number and size of target lesions the posttherapy morphological tumor changes.
\end{abstract}

Keywords: Colorectal liver metastases; Colorectal cancer; Oncosurgical strategy; Conversion to resectability; Resectability criteria; Therapeutic response criteria

Abbreviation: CRLM: Colo-Rectal cancer Liver Metastases; LMs: Liver Metastases; CRC: Colo-Rectal Cancer; CRR: Conversion to Resectability Rate; ADPT: Absolute Disease Progression Time Interval; ADPR: Absolute Disease Progression Rate

\section{Introduction}

Colorectal cancer is the third most common cancer worldwide among men (incidence 21 per 100,000 and mortality rate 10 per 100,000 ) and the second among women (incidence 15 per 100,000 and mortality rate 8 per 100,000). In Central and Eastern Europe, the incidence is 35 per 100,000 men and 22 per 100,000 women and mortality rate 20.3 per 100,000 men and 11.7 per 100,000 women. The overall 5 year survival rate is $50-60 \%$ [1].

These rather disappointing results are mainly due to (remote) secondary lesions that most commonly affect the liver. Liver metastases occur in approximately $50 \%$ of all patients with CRC and represent the main cause of death. They are present in $15-25 \%$ of patients at the time of diagnosis [2-4].

Despite the recent progress in the multi-disciplinary treatment for stage IV CRC, the 5 -year survival is only $6 \%$ However, the survival rate has improved considering that 10 years ago, stage IV CRC was associated with a 5 -year survival of less than $1 \%$ [5].

Surgical treatment - the resection of metastases - remains the only curative treatment for CRLM. The complete resection of all liver metastases improves the overall survival from $25 \%$ (R1) to $40 \%$ (R0) $[4,6]$. Granting all this, the relapse / recurrence rate after curative liver resections remains high, ranging from $50 \%$ to $70 \%$ [7].

These fluctuations in survival rate are mainly related to the selection of the indications for liver resection. The benefits are due to the imaging techniques, which offer a better choice of surgical procedures. Also, the development of other complementary techniques (portal vein embolization, thermoablation) and oncological therapies (chemotherapy, molecular therapy) have increased patient eligibility

*Corresponding author: Timofeiov S, Bd. Independentei nr. 1, 700111, lasi, Romania, Tel/Fax: +40 2322408 22; E-mail: stimof@yahoo.com

Received October 25, 2014; Accepted April 29, 2015; Published May 05, 2015

Citation: Timofeiov S, Marinca M, Bar C, Breabăn ME, Drug V, et al. Conversion Rate to Resectability in Colorectal Cancer Liver Metastases: Need for Criteria Adapted to Current Therapy.. Journal of Surgery [Jurnalul de chirurgie] 2015; 11(1): 323-336 DOI:10.7438/1584-9341-11-1-4

Copyright: (C) 2015 Timofeiov S, et al. This is an open-access article distributed under the terms of the Creative Commons Attribution License, which permits unrestricted use, distribution, and reproduction in any medium, provided the original author and source are credited. 
for resection of liver metastases (LMs). Currently, 25-30\% of all patients with CRC and liver metastases may benefit from liver resection $[8,9]$. It has been proved that for patients with synchronous LM who received both pre and post-op chemotherapy, there was a significantly increased percentage of survival, without escalation of the neoplastic disease [10]. The median survival rate for patients with untreated colorectal LMs ranges between 4.5 and 15 months; patients who survived 5 years were also recorded.

The monitoring of surgically treated CRC patients (with or without LMs) was analyzed by randomized prospective studies, which showed an absolute reduction rate of $10 \%$ in the 5 -year mortality rate. The early identification of a relapse, which is possible under a strict surveillance, results in an average survival increase of 8.5 months, compared with the absence of such surveillance $[11,3]$.

Intensive surveillance is associated with a higher rate of resectability for metastases ( $76 \%$ vs 56\%), the diagnosis of smaller liver metastases $(3 \mathrm{~cm} v s \mathrm{~cm})$ and an improved survival rate $(26.8 \% v s 12.5 \%$ at 3 year survival) $[12,13]$.

\section{Material and Method}

\section{Patients}

This study represents an 18 months prospective analysis based on surveillance protocols of patients with liver metastases of colorectal cancer, which was used in the First Surgical Clinic of the Regional Institute of Oncology (IRO) Iaşi, Romania. The origin of this protocol is a classification of patients into 4 groups of resectability of liver metastases: clearly resectable, possibly resectable, susceptible resectable and unresectable metastases (Table I). Inclusion criteria:

Age: over 18 years

- Pathology: diagnosis of colorectal carcinoma

- Imaging diagnosis: (CT / MRI) of liver metastases

- $\quad$ Signed informed consent

- Accepts to follow exactly the treatment proposed by the Oncologic Committee of IRO

\section{Exclusion Criteria:}

Age: under 18 years

Diagnosis of rare colorectal cancer (sarcoma, lymphoma, melanoma, endocrine tumors, carcinoid tumor)
Cancer with particular location (anal canal, appendix)

Does not fully accept the treatment proposed by the Oncologic Committee of IRO

\section{Diagnosis}

The clinical diagnosis was made by the surgeon treating the patient and confirmed by a second, independent surgeon. The diagnosis was confirmed after the analysis of the results of the following investigations: morpho-pathology of the primary tumor (biopsy or resection piece), colonoscopy, imaging (abdominal CT / MRI), radiology (chest X-ray +/- chest CT), and immunology (CEA: Carcino Embryonic Antigen).

Tumor staging was done according to the $7^{\text {th }}$ edition of TNM stage criteria for colorectal cancer provided by the American Joint Committee on Cancer (AJCC). The criteria for classifying the patients into the 4 groups are shown in Table 1 [14].

\section{Treatment}

In order to better standardize the study, the surgical interventions were divided into:

Interventions on the primary tumor

Curative resection (right or left colectomies, total colectomies, anterior rectal resections, abdomino-perineal rectum excisions, Hartmann procedures);

Palliative interventions (digestive bypass colostomy).

Interventions on liver metastases

Minor liver resections ( $\leq 3$ liver segments);

Major liver resections (> 3 liver segments).

Complementary interventions ("adjuvant")

Local therapy (thermoablation, portal vein ligature, port-a-cath insertion into the hepatic artery);

Complementary oncological interventions (excision of lymph node recurrences, peritoneal biopsy, liver biopsy, loco-regional lymphadenectomy - usually associated with major resections);

Interventional radiology procedures (hepatic portal vein embolization and chemoembolization artery).

\section{Associated interventions}

Represent interventions for keeping a radical intervention (block

Tabel I: The criteria for classifying patients into study groups [14].

\begin{tabular}{|c|c|}
\hline Study groups & Criteria for patient assignment to \\
\hline \multirow{5}{*}{ Group I - CLEAR resectabilityn=27 $(25.47 \%)$} & - maximum 3 unilateral LMs, away from vessels \\
\hline & - resection of maximun 4 liver segments \\
\hline & - at least $40 \%$ remaining liver parenchyma \\
\hline & - normal functional status of remaining liver parenchyma \\
\hline & - absence of extrahepatic metastases \\
\hline \multirow{5}{*}{ Group II - POSSIBLY resectabilityn=13 (12.26\%) } & - LMs with vascular contact \\
\hline & - need for complex, extended resection \\
\hline & $-25-30 \%$ remaining liver parenchyma \\
\hline & - normal functional status of remaining liver parenchyma \\
\hline & - absence of extrahepatic metastases \\
\hline \multirow{3}{*}{ Group III - SUSCEPTIBLE resectabilityn=15 (14.15\%) } & - multiple, bilateral LMs, but with a clear unilateral predominance \\
\hline & - insufficient functional status of remaining liver parenchyma \\
\hline & - possible but resectable extrahepatic metastases \\
\hline \multirow{3}{*}{ Group IV - UNRESECTABLE metastastasesn=51 (48.11\%) } & - multiple, bilateral LMs \\
\hline & - presence of unresectable extrahepatic metastases \\
\hline & $\begin{array}{l}\text { - unresectable primary tumor, recurrence, or contined primary tumor progression } \quad \text { (imaging or bioptic } \\
\text { confirmation) }\end{array}$ \\
\hline
\end{tabular}


resection) or interventions without any influence on the development of neoplastic disease (hysterectomy, Hartmann's reversal, enterectomy, appendectomy, cholecystectomy, inguinal hernia surgical repair, surgical repair of incisional hernia).

For patients with a resectable primary tumor and resectable synchronous LMs (clearly or possibly resectable) the therapeutic approach was as follows:

- Simultaneous resection (primary tumor and liver metastases), possible in primary tumors that are relatively easily resectable (right colon, sigmoid and less in rectal cancer) associated with minor hepatectomy ( $\leq 3$ resected liver segments); preferable when the duration of surgery and intraoperative incidents (bleeding) do not affect the patient's postoperative recovery;

- Staged resection (primary tumor resection without liver metastases approach, but with intent to be removed after cancer treatment); it is used especially in cases where the patient's condition does not allow for another surgical sequence.

For patients with an unresectable primary tumor and resectable synchronous LMs, the surgical treatment was palliative (colostomy, digestive bypass) without resection of the liver metastases. The "Liver first approach" strategy (a reversed treatment sequence in which the
CRLM are resected before the primary carcinoma) was not used. The therapeutic options for each group are listed in Table 2.

For thermoablation of the LMs an ultrasonic generator system was used (SonoSurg G2). Hepatic artery chemoembolization (Seldinger technique) and portal vein embolization (trans-parietal) were performed at the Radiology Unit of the "Sf. Spiridon" Hospital, Iasi, Romania.

Curative chemotherapy (neo-adjuvant, induction, and adjuvant) and palliative chemotherapy were administered according to the guidelines suggested by the NCCN (National Comprehensive Cancer Network). First line chemotherapy consisted in one of the regimens shown in Table 3. After the first tumor progression the regimen was changed (second-line chemotherapy). After the second tumor progression, the regimen was once again changed (third line chemotherapy) or a palliative treatment was initiated, depending on the patient's general condition and their tolerance to chemotherapy. Palliative or symptomatic treatment was initiated after the third tumor progression.

Although not generally agreed on by all oncologists, this division of chemotherapy as "neo-adjuvant", "induction", and "adjuvant" helps to assess the treatment response in terms of goal and expectation. It is argued that neo-adjuvant chemotherapy is administered to patients

Tabel II: Therapeutic options by study group.

\begin{tabular}{|c|c|}
\hline Study groups & Onco-surgical options \\
\hline \multirow{6}{*}{ Group I } & - primary tumor resection and LMs resection simultaneous or staged (synchronous LMs) \\
\hline & - resection of metachronous LMs \\
\hline & - port-a-cath insertion into the hepatic artery \\
\hline & - systemic neoadjuvat chemothrapy (after primary tumor resection - in patients with synchronous LMs pending ",hepatic sequence”) \\
\hline & $\begin{array}{l}\text { - systemic +/- locoregional adjuvat chemotherapy (after LMs resection - simultaneous with primary tumor ressection in patients with synchronous } \\
\text { LMs or in patients with metachronous LMs) }\end{array}$ \\
\hline & - monoclonal antibody targeted therapy (anti-EGFR, anti-VEGF) \\
\hline \multirow{7}{*}{ Group II } & - primary tumor resection and staged LMs resection (synchronous LMs) \\
\hline & - resection of metachromous LMs (depending on the opporunity of a major hepatectomy) \\
\hline & - port-a-cath insertion into the hepatic artery \\
\hline & - systemic neoadjuvant chemotherapy (after primary tumor resection - in patients with synchronous LMs pending „hepatic sequence”) \\
\hline & - systemic +/-locoregional adjuvat chemotherapy (after LMs resection - in patients with metachromous LMs) \\
\hline & - monoclonal antibody targeted therapy (anti-EGFR, anti-VEGF) \\
\hline & - reassessment of the opportunity of LMs resection depending on the response to treatment \\
\hline \multirow{8}{*}{ Group III } & - primary tumor resection (synchronous LMs) \\
\hline & - port-a-cath insertion into the hepatic artery \\
\hline & - thermoablation (only if is possible for all LMs from one liver lobe, in association with portal vein embolization / ligature) \\
\hline & - portal vein embolization / ligature \\
\hline & - hepatic arterial chemoembolization \\
\hline & - systemic induction chemotherapy (in patients with metachronous LMs or in patients with synchronous LMs following primary tumor resection) \\
\hline & - monoclonal antibody targeted therapy (anti-EGFR, anti-VEGF) \\
\hline & - reassessment of the opportunity of LMs resection depending on the response to cancer treatment \\
\hline \multirow{6}{*}{ Group IV } & - primary tumor resection (synchronous LMs and resectable primary tumors) \\
\hline & - digestive bypass or colostomy (synchronous LMs and unresectable primary tumors) \\
\hline & - port-a-cath insertion into the hepatic artery \\
\hline & - hepatic arterial chemoembolization \\
\hline & - systemic palliative chemotherapy \\
\hline & - monoclonal antibody targeted therapy (anti-EGFR, anti-VEGF) \\
\hline
\end{tabular}


Table III: Protocol of chemotherapy for metastatic colorectal cancer ${ }^{*}$.

\begin{tabular}{|c|c|}
\hline Chemotherapy regimens & Posology \\
\hline \multirow{5}{*}{ Capecitabine + /- bevacizumab or cetuximab } & - capecitabine $850-1250 \mathrm{mg} / \mathrm{m} 2$ po twice daily, days $1-14$ \\
\hline & Repeat every 3 weeks \\
\hline & - bevacizumab $7.5 \mathrm{mg} / \mathrm{kg}$ iv, day 1 \\
\hline & - cetuximab $500 \mathrm{mg} / \mathrm{m} 2 \mathrm{iv}$, over 2 hours, day 1 \\
\hline & (KRAS/NRAS WT gene only) \\
\hline \multirow{6}{*}{ FOLFOX $+/$ - bevacizumab or cetuximab } & - oxaliplatin 85 mg/m2 iv, over 2 hours, day 1 \\
\hline & - leucovorin $400 \mathrm{mg} / \mathrm{m} 2$ iv, over 2 hours, day 1 \\
\hline & - 5 -FU $400 \mathrm{mg} / \mathrm{m} 2$ iv bolus day 1 , then $1200 \mathrm{mg} / \mathrm{m} 2$ /day×2days iv continuous infusion \\
\hline & Repeat every 2 weeks \\
\hline & - bevacizumab $5 \mathrm{mg} / \mathrm{kg}$ iv, 1 day, every 2 weeks \\
\hline & - cetuximab 500 mg/m2 iv, over 2 hours, day 1 , every 2 weeks (KRAS/NRAS WT gene only) \\
\hline \multirow{5}{*}{ CapeOX $+/$ - bevacizumab or cetuximab } & - oxaliplatin $130 \mathrm{mg} / \mathrm{m} 2$ iv, over 2 hours, day 1 \\
\hline & - capecitabine $850-1000 \mathrm{mg} / \mathrm{m} 2$ twice daily po for 14 days \\
\hline & Repeat every 3 weeks \\
\hline & - bevacizumab $7.5 \mathrm{mg} / \mathrm{m} 2$ iv, 1 day, every 2 weeks \\
\hline & - cetuximab $500 \mathrm{mg} / \mathrm{m} 2$ iv, over 2 hours, day 1 , every 2 weeks (KRAS/NRAS WT gene only) \\
\hline \multirow{6}{*}{ FOLFIRI +/- bevacizumab or cetuximab } & - irinotecan $180 \mathrm{mg} / \mathrm{m} 2$ iv, over 30-90 minutes, day 1 \\
\hline & - leucovorin $400 \mathrm{mg} / \mathrm{m} 2 \mathrm{iv}$, infusion to match duration of irinotecan, day 1 \\
\hline & - 5-FU $400 \mathrm{mg} / \mathrm{m} 2$ iv bolus day then $1200 \mathrm{mg} / \mathrm{m} 2 /$ day $\times 2$ days iv continuous infusion \\
\hline & Repeat every 2 weeks \\
\hline & - bevacizumab $5 \mathrm{mg} / \mathrm{m} 2$ iv, 1 day, every 2 weeks \\
\hline & - cetuximab 500 mg/m2 iv, over 2 hours, day 1, every 2 weeks (KRAS/NRAS WT gene only) \\
\hline \multirow{3}{*}{ IROX } & - oxaliplatin $85 \mathrm{mg} / \mathrm{m} 2$ iv, over 2 hours, followed by \\
\hline & - irinotecan $200 \mathrm{mg} / \mathrm{m} 2$ iv, over 30-90 minutes, day 1 \\
\hline & Repeat every 3 weeks \\
\hline \multirow{3}{*}{ FUFOL (5-FU/LV) } & - leucovorin $500 \mathrm{mg} / \mathrm{m} 2$ iv, over 2 hours, weekly, 6 weeks \\
\hline & - 5-florouracil (5-FU) $500 \mathrm{mg} / \mathrm{m} 2$ iv, bolus 1 hour after start of leucovorin, weekly, 6 weeks \\
\hline & Repeat every 8 weeks \\
\hline
\end{tabular}

"NCCN Guidelines.

with tumors considered resectable, therefore optional but recommended. Induction chemotherapy is administered to patients with borderline resectable or unresectable tumors, so it is a therapy of necessity, its goal being tumor "downsizing" and "downstaging" to resectability.

\section{Assessment of Treatment Response}

According to the scientific surveillance protocol, CRLM patients should be assessed at the time of admission (study entry) and every 3 months for the first 2 years, then every 6 months for the next 3 years based on clinical examination, chest Xray +/- chest CT, abdominal CT/ MRI, ACE. Colonoscopy should be done every 2 years or when suspecting (clinically or by imaging ) a primary tumor recurrence. We considered as patients "lost from follow-up" those who did not come back as scheduled for their surgical / oncological reassessment, without being able to confirm the death of the patient, or those who waived the treatment proposed by the Oncology Commission. The rationale behind performing evaluations every 3 months is that this period corresponds roughly to 3 cycles of chemotherapy (the average number of chemotherapy cycles for CRLM, after which any imaging changes can be noticed) .

The imaging evaluation of therapeutic response was based on the abdominal CT, interpreted using RECIST criteria. For all the investigations, baseline evaluation and follow-up, we used the same imaging protocol with the following scanning parameters:

- Native scan (pre-contrast scan) biphasic approach after intravenous contrast injection (arterial and portal phase) using bolus triggering for CT Siemens 16 slice or test injection for CT Philips Brilliance 6 slice;

- Effective section width (ESW) was less than or equal to $5 \mathrm{~mm}$, and remained constant at all assessments (baseline and follow-up);
- Continuous sections of $3 / 3 \mathrm{~mm}, 4 / 4 \mathrm{~mm}$ or $5 / 5 \mathrm{~mm}$;

- Intravenous contrast: iodine concentration $370 \mathrm{mg} / \mathrm{ml}$, amount $1.2 \mathrm{ml} / \mathrm{kg}$, flow rate $3-4 \mathrm{ml} / \mathrm{s}$;

- oral contrast prior to examination $500 \mathrm{ml}$ over 30 minutes before the examination (only for liver examination), 1000-1500 ml over 60 minutes before the examination (only for abdominal-pelvic examination);

- Rectal contrast - between 500 - 1000 - $2000 \mathrm{ml}$ if the examination of the rectum and colon was also intended;

- Scanned volume includes the lungs apices to the pubis symphysis or above the diaphragm to the pubis symphysis. The used RECIST criteria are shown in Table 4 [15].

\section{Statistical Interpretation}

The data for the study was collected from the IRO Iasi electronic system, the patient surgery protocols and the medical records in the IRO Iasi archives. The database was processed in MS Excel, and statistical analysis was performed using RStudio software. Student $t$ test, Pearson- $\chi^{2}$, Fisher exact test, and ANOVA tests were used. Significance threshold was $\mathrm{p}<0.05$.

For this study we defined three notions:

1. Conversion to resectability rate (CRR)

$\mathrm{CRR}=\frac{\text { patients in groups } \mathrm{II}+\mathrm{III} \text { who became resectable }}{\text { total }}$

2. Absolute disease progression time interval (ADPT) 
Table IV: RECIST criteria*.

\begin{tabular}{|l|l|}
\hline Therapeutic response & Size and number imaging criteria \\
\hline Complete Response (CR) & - disappearance of all target lesions \\
\cline { 2 - 3 } & - any pathological lymph nodes (whether target or non-target) must have reduction in short axis to <10 mm. \\
\hline Partial Response (PR) & - at least a $30 \%$ decrease in the sum of diameters of target lesions, taking as reference the baseline sum diameters. \\
\hline Progressive Disease (PD) & $\begin{array}{l}\text { - at least a } 20 \% \text { increase in the sum of diameters of target lesions, taking as reference the smallest sum on study (this includes the } \\
\text { baseline sum if that is the smallest on study); in addition tothe relative increase of } 20 \%, \text { the sum must also demonstrate an absolute } \\
\text { increase of least } 5 \mathrm{~mm}\end{array}$ \\
\hline - the appearance of one or more new lesions \\
\hline Stable Disease (SD) & $\begin{array}{l}\text { - neither sufficient shrinkage to qualify for PR nor sufficient increase to qualify for PD, taking as reference the smallest sum diameters while } \\
\text { on study }\end{array}$ \\
\hline
\end{tabular}

*RECIST Working Group guideline (version 1.1)

$\mathrm{ADPT}=[$ from study enrollment, to the date when the patient became unresectable]

3. Absolute disease progression rate (ADPR)

$\mathrm{ADPR}=\frac{\text { patients in groups II }+ \text { III who became unresectable }}{\text { total number of patients in groups II }+ \text { III }}$

The aim of this study was to evaluate CRR, ADPT, and ADPR. Also, this study is trying to demonstrate the need for a surveillance protocol of patients with CRLM.

\section{Results}

Between June 1, 2012 and December 31, 2013, there were 106 patients admitted at the First Surgical Oncology Unit of IRO Iasi with CRLH diagnosis, which met the inclusion criteria into the study. These patients were divided into 4 groups according to the criteria shown in Table 1, each group representing a class of liver metastases resectability.

The general characteristics of patients (age, sex), comorbidities (interpreted by ASA score and Charlson Comorbidity Index Risk) and staging of the primary tumor based on the analysis of morphopathology report are shown in Table 5.

The average age of the statistical community was 63.17 years (range 37-90). The distribution of the patients along the 4 groups was relatively homogeneous with regard to their age; the ANOVA test does not reveal any significant difference in this regard $(\mathrm{F}=0.624, \mathrm{p}=0.60)$.

Of all the patients included in the study, 63.21\% ( $\mathrm{n}=67)$ were men and $36.79 \%(n=39)$ women. The Fisher test does not indicate a significant dependence between the group type and the gender of the patients $(\mathrm{p}=0.3915)$.

Not all patients had associated diseases; 11 patients did not present any comorbidity. Analysis of associated disorders revealed a large number of cardiovascular diseases $(n=108)$ followed at a distance by digestive diseases $(n=43)$. The identified oncologic diseases included: synchronous cancer (colon) in 2 patients, metachronous cancers (breast, colon, ovarian, mesenteric) in 4 patient, and local tumor recurrences in 5 patients.

There was a very strong association between the study groups and life expectancy expressed as Charlson Comorbidity Index $(\mathrm{p}=0.0002639)$. A strong dependence was found between resectability classes and anesthetic risk expressed as ASA Score $(\mathrm{p}=0.01062)$.

Analysis of morpho-pathology reports for the primary tumors revealed only one T1case in group II, the remaining cases presenting a high degree of local invasion and being relatively evenly distributed: 49 patients (46.23\%) with tumors exceeding the muscularis propria (T3) and 56 patients $(52.83 \%)$ with tumors exceeding the visceral peritoneum and / or invading the neighboring organs (T4a, b). In almost half of the patients $(n=45,42.45 \%)$, metastases were found in less than 3 lymph nodes (N1). The dominant tumor grade was G2 (moderately differentiated) being observed in 41 patients $(38.68 \%)$. These are summarized in Table 5.

Carcinoembryonic antigen (CEA) is a marker of first choice for colorectal cancer and was collected from all study patients before treatment. CA 19-9 is a marker of first choice for pancreatic cancer, but may be high in colorectal cancer and was also collected from all study patients before treatment. The levels of the two tumor markers in the four study groups are shown in Table 6.

Chest X-rays were routinely performed for all patients, both for detection of pulmonary metastases and for the preoperative evaluation of the patient, even though not included in RECIST. Thus 14 patients (13.2\%) with lung metastases were identified; in 2 cases, presenting a probable resectability of lung metastases, the performed chest CT infirmed the resectability of lesions.

Abdominal CT showed that LMs were most frequently multiple and bilobar $(n=26)$, followed by those located in segment VIII $(n=16)$, as seen in Table 7. Fisher's exact test indicates statistically significant differences between the number of LMs in each segment and the 4 study groups for liver sections IVa, IVb, V, VI, and VII. A total volumetric assessment of LMs and normal healthy liver parenchyma was not possible in every patient.

The therapeutic characteristics, response to treatment, and postoperative complications (according to Clavien-Dindo classification) for all 4 study groups are presented in Tables 7-11.

Apparently difficult to analyze, Tables 7-11 must be interpreted from the initial surgical and oncological treatment to the 3 month treatment response, and, based on this response, follow on to the interpretation of the treatment performed. Therefore, in a column can be followed the treatment response during the last 3 months; according to this response the treatment for the next 3 months is established. Notes with explanations (a-s) are the same for all tables VII - XI and are found at the end of the table XI.

After dividing the patients into study groups it was found that only $25.47 \%$ of patients (group I) were eligible for safe liver resection and $48.11 \%$ (group IV) were not candidates for curative treatment.

Data analysis for the entire statistical collectivity highlights the following aspects:

Surgical procedures with curative intent on primary tumor for 55 patients, palliative surgery for 14 patients; five patients were inoperable and 32 patients had primary tumor resection in their history;

Complementary interventions were performed to 59 patients;

Associated interventions were performed to 24 patients;

Liver resections were performed in 34 patients (15 major +19 minor), accounting for $32.07 \%$ of all patients; of these, 7 patients $(6.66 \%)$ with possible or susceptible resectability were converted to resectability 
Table V: Patients and tumor characteristics.

\begin{tabular}{|c|c|c|c|c|c|c|}
\hline \multirow{3}{*}{ Variables } & Lot I & Lot II & Lot III & Lot IV & Total & \multirow{3}{*}{ p-value } \\
\hline & $\mathrm{n}=\mathbf{2 7}$ & $n=13$ & $n=15$ & $\mathrm{n}=51$ & $n=106$ & \\
\hline & $(25.47 \%)$ & $(12.26 \%)$ & $(14.15 \%)$ & $(48.11 \%)$ & & \\
\hline Age (mean) & 60.96 & 63.69 & 66.06 & 63.37 & 63.17 & (ANOVA) 0.6 \\
\hline \multicolumn{7}{|c|}{ Gender } \\
\hline \multirow{2}{*}{ Male } & 19 & 10 & 10 & 28 & 67 & \multirow{4}{*}{ (Fisher) 0.3915} \\
\hline & $70.37 \%$ & $76.92 \%$ & $66.66 \%$ & $54.90 \%$ & $63.21 \%$ & \\
\hline \multirow{2}{*}{ Female } & 8 & 3 & 5 & 23 & 39 & \\
\hline & $29.62 \%$ & $23.07 \%$ & $33.33 \%$ & $45.09 \%$ & $36.79 \%$ & \\
\hline \multicolumn{7}{|c|}{ ASA Score } \\
\hline \multirow{2}{*}{ I } & 8 & 1 & 6 & 10 & 26 & \multirow{6}{*}{ (Fisher) 0.01062} \\
\hline & $29.62 \%$ & $7.69 \%$ & $40.00 \%$ & $19.60 \%$ & $24.52 \%$ & \\
\hline \multirow{2}{*}{ I } & 16 & 10 & 7 & 19 & 54 & \\
\hline & $59.25 \%$ & $76.92 \%$ & $46.66 \%$ & $37.25 \%$ & $50.95 \%$ & \\
\hline \multirow{2}{*}{$\mathrm{III}+$} & 3 & 2 & 2 & 22 & 26 & \\
\hline & $11.11 \%$ & $15.38 \%$ & $13.33 \%$ & $43.14 \%$ & $24.52 \%$ & \\
\hline \multicolumn{7}{|c|}{ Charlson Comorbidity Index } \\
\hline \multirow{2}{*}{6} & 4 & 1 & 6 & 11 & 22 & \multirow{6}{*}{ (Fisher) 0.0002} \\
\hline & $14.81 \%$ & $7.69 \%$ & $40.00 \%$ & $21.56 \%$ & $20.75 \%$ & \\
\hline \multirow{2}{*}{7} & 18 & 3 & 1 & 28 & 50 & \\
\hline & $66.66 \%$ & $23.07 \%$ & $6.66 \%$ & $54.90 \%$ & $47.17 \%$ & \\
\hline $8+$ & 5 & 9 & 8 & 12 & 34 & \\
\hline $\mathbf{O}^{\mathbf{4}}$ & $18.52 \%$ & $69.23 \%$ & $53.33 \%$ & $23.53 \%$ & $32.07 \%$ & \\
\hline \multicolumn{7}{|c|}{ pTNM-stage } \\
\hline \multirow{2}{*}{ T1 } & 0 & 1 & 0 & 0 & 1 & \\
\hline & 0 & $7.69 \%$ & 0 & 0 & $0.94 \%$ & \\
\hline T2 & 0 & 0 & 0 & 0 & 0 & \\
\hline$T 3$ & 16 & 8 & 10 & 15 & 49 & (Fisher) 0.0031 \\
\hline 10 & $59.25 \%$ & $61.53 \%$ & $66.66 \%$ & $29.41 \%$ & $46.23 \%$ & \\
\hline$T A a^{2}$ & 11 & 4 & 5 & 36 & 56 & \\
\hline $14 \mathrm{a}, \mathrm{D}$ & $40.74 \%$ & $30.76 \%$ & $33.33 \%$ & $70.59 \%$ & $52.83 \%$ & \\
\hline NO & 6 & 0 & 0 & 11 & 17 & \\
\hline NO & $22.22 \%$ & 0 & 0 & $21.57 \%$ & $16.03 \%$ & \\
\hline N1 & 11 & 6 & 7 & 21 & 45 & (Fichort 02170 \\
\hline $\mathbf{N 1}$ & $40.74 \%$ & $46.15 \%$ & $46.66 \%$ & $41.17 \%$ & $42.45 \%$ & (FISher) $0.24 / 3$ \\
\hline Q2 & 10 & 7 & 8 & 19 & 44 & \\
\hline $\mathbf{N} 2$ & $37.03 \%$ & $53.84 \%$ & $53.33 \%$ & $37.25 \%$ & $41.51 \%$ & \\
\hline & & & G-grading & & & \\
\hline G1 & 9 & 0 & 2 & 4 & 15 & \\
\hline $\mathbf{G}$ & $33.33 \%$ & 0 & $13.33 \%$ & $7.84 \%$ & $14.15 \%$ & \\
\hline 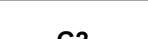 & 9 & 8 & 3 & 21 & 41 & \\
\hline $\mathbf{G} 2$ & $33.33 \%$ & $61.54 \%$ & $20.00 \%$ & $41.17 \%$ & $38.68 \%$ & \\
\hline$m_{3}$ & 7 & 5 & 7 & 20 & 39 & (Fichar) $<00001$ \\
\hline ⿶3 & $25.93 \%$ & $38.46 \%$ & $46.66 \%$ & $39.22 \%$ & $36.79 \%$ & (FIster) \\
\hline 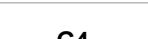 & 2 & 0 & 0 & 6 & 8 & \\
\hline $\mathbf{G}_{4}$ & $7.40 \%$ & 0 & 0 & $11.76 \%$ & $7.55 \%$ & \\
\hline$a_{x}$ & 0 & 0 & 3 & 0 & 3 & \\
\hline GX & 0 & 0 & $20.00 \%$ & 0 & $2.83 \%$ & \\
\hline Variables & & Group I & Group II & Group III & Group IV & p-value (ANOVA) \\
\hline & minimum & 1.28 & 1.05 & 1.86 & 2.1 & \\
\hline CF & maximum & 958 & 1487 & 2220 & 6331 & 171 \\
\hline ACE & mean value & 66.95 & 208.66 & 376.01 & 422.45 & $0.4 / 1$ \\
\hline & standard deviation & 211.47 & 487.79 & 706.57 & 1154.09 & \\
\hline & minimum & 0.6 & 2.78 & 6.61 & 0.85 & \\
\hline $0 \wedge 100$ & maximum & 325.9 & 273.3 & 95.82 & 2695 & $010^{-7}+2$ \\
\hline CA $19-9$ & mean value & 49.87 & 63.7 & 41.25 & 310.8 & 0.117 \\
\hline & standard deviation & 76.6 & 91.95 & 31.27 & 611.96 & \\
\hline
\end{tabular}


Table VII: Main CT characteristics of hepatic metastases.

\begin{tabular}{|c|c|c|c|c|c|c|}
\hline & Group I & Group II & Group III & Group IV & Total & p-value (Fisher) \\
\hline \multicolumn{7}{|c|}{ Number of LMs } \\
\hline \multicolumn{7}{|c|}{ LMs limited to 1 segment } \\
\hline 1 & 0 & 0 & 0 & 3 & 3 & 0.8213 \\
\hline II & 1 & 3 & 1 & 3 & 8 & 0.1753 \\
\hline III & 0 & 2 & 1 & 2 & 5 & 0.0973 \\
\hline IVa & 2 & 6 & 2 & 0 & 10 & $<0.0001$ \\
\hline $\mathrm{IVb}$ & 3 & 4 & 1 & 0 & 8 & 0.0013 \\
\hline V & 6 & 4 & 3 & 0 & 13 & 0.0002 \\
\hline $\mathrm{VI}$ & 7 & 4 & 3 & 0 & 14 & 0.0001 \\
\hline VII & 6 & 3 & 3 & 0 & 12 & 0.0004 \\
\hline VIII & 6 & 4 & 3 & 3 & 16 & 0.0295 \\
\hline LMs limited to 2 segments & 0 & 0 & 1 & 6 & 7 & 0.2399 \\
\hline LMs limited to 3 segments & 0 & 0 & 1 & 5 & 6 & 0.2998 \\
\hline Multiple, bilobar LMs & 0 & 0 & 4 & 22 & 26 & $<0.0001$ \\
\hline \multicolumn{7}{|c|}{ Size of LMs } \\
\hline minimum & $6 \mathrm{~mm}$ & $7 \mathrm{~mm}$ & \multicolumn{2}{|c|}{$5 \mathrm{~mm}$} & $5 \mathrm{~mm}$ & n.a. \\
\hline maximum & $38 \mathrm{~mm}$ & $38 \mathrm{~mm}$ & \multicolumn{2}{|c|}{$95 \mathrm{~mm}$} & $95 \mathrm{~mm}$ & n.a. \\
\hline
\end{tabular}

Table VIII: Treatment, therapeutic response and postoperative surgical complications in group I 27 patients (19 synchronous LMs + 8 metachronous LMs.

\begin{tabular}{|c|c|c|c|c|}
\hline Variables & Baseline evaluation & At 3 months & At 6 months & At 9 months \\
\hline \multicolumn{5}{|l|}{ Surgical Treatment } \\
\hline \multicolumn{5}{|l|}{ Primary tumor } \\
\hline $\begin{array}{l}\text { curative intent resection }{ }^{\mathrm{a}} \text { (simultaneous + } \\
\text { staged) }\end{array}$ & $12+7(70.37 \%)$ & n.a. & n.a. & n.a. \\
\hline palliative interventions ${ }^{b}$ & $0(0.0 \%)$ & n.a. & n.a. & n.a. \\
\hline previous resection $^{c}$ & $8(29.62 \%)$ & n.a. & n.a. & n.a. \\
\hline \multicolumn{5}{|l|}{ Liver metastases } \\
\hline minor resection $^{d}$ & $13(48.14 \%)$ & $3(11.11 \%)$ & $3(11.11 \%)$ & $0(0.0 \%)$ \\
\hline major resection ${ }^{e}$ & $7(25.92 \%)$ & $0(0.0 \%)$ & $1(3.70 \%)$ & $0(0.0 \%)$ \\
\hline positive resection margins & $0(0.0 \%)$ & $0(0.0 \%)$ & $0(0.0 \%)$ & $0(0.0 \%)$ \\
\hline Complementary interventions ${ }^{f}$ & $11(40.74 \%)$ & $2(7.40 \%)$ & $2(7.40 \%)$ & $2(7.40 \%)$ \\
\hline Associated interventions ${ }^{g}$ & $10(37.03 \%)$ & $0(0.0 \%)$ & $4(14.80 \%)$ & $0(0.0 \%)$ \\
\hline Unoperated patients ${ }^{h}$ & $0(0.0 \%)$ & $0(0.0 \%)$ & $0(0.0 \%)$ & $0(0.0 \%)$ \\
\hline \multicolumn{5}{|l|}{ Oncological Treatment } \\
\hline neoadjuvant chemotherapyi & $7(25.92 \%)$ & $4(14.80 \%)$ & $0(0.0 \%)$ & $0(0.0 \%)$ \\
\hline adjuvant chemotherapy ${ }^{j}$ & $20(74.06 \%)$ & $23(85.18 \%)$ & $27(100 \%)$ & $27(100 \%)$ \\
\hline induction chemotherapy ${ }^{k}$ & $0(0.0 \%)$ & $0(0.0 \%)$ & $0(0.0 \%)$ & $0(0.0 \%)$ \\
\hline palliative chemotherapy & $0(0.0 \%)$ & $0(0.0 \%)$ & $0(0.0 \%)$ & $0(0.0 \%)$ \\
\hline molecular therapy' & $2(7.40 \%)$ & $11(40.74 \%)$ & $12(44.44 \%)$ & $12(44.44 \%)$ \\
\hline \multicolumn{5}{|l|}{ Treatment Response } \\
\hline \multicolumn{5}{|l|}{ RECIST $^{\mathrm{m}}$} \\
\hline partial response ${ }^{n}$ & n.a. & $2(7.40 \%)$ & $4(14.80 \%)$ & $0(0.0 \%)$ \\
\hline complete reponse $^{\circ}$ & n.a. & $0(0.0 \%)$ & $0(0.0 \%)$ & $0(0.0 \%)$ \\
\hline stable disease & n.a. & $25(92.59 \%)$ & $23(85.18 \%)$ & $27(100 \%)$ \\
\hline progressive disease & n.a. & $0(0.0 \%)$ & $0(0.0 \%)$ & $0(0.0 \%)$ \\
\hline \multicolumn{5}{|l|}{ Site of tumor progression } \\
\hline primary tumor $^{p}$ & n.a. & $0(0.0 \%)$ & $0(0.0 \%)$ & $0(0.0 \%)$ \\
\hline Liver $^{r}$ & n.a. & $0(0.0 \%)$ & $0(0.0 \%)$ & $0(0.0 \%)$ \\
\hline Extrahepatics & n.a. & $0(0.0 \%)$ & $0(0.0 \%)$ & $0(0.0 \%)$ \\
\hline mixed & n.a. & $0(0.0 \%)$ & $0(0.0 \%)$ & $0(0.0 \%)$ \\
\hline Non-surgical mortality & $0(0.0 \%)$ & $0(0.0 \%)$ & $0(0.0 \%)$ & $0(0.0 \%)$ \\
\hline \multicolumn{5}{|c|}{ Postoperative Surgical Complications (Clavien-Dindo Classification) } \\
\hline Grade I & $13(48.14 \%)$ & $0(0.0 \%)$ & $1(3.70 \%)$ & $0(0.0 \%)$ \\
\hline Grade II & $8(29.62 \%)$ & $2(7.40 \%)$ & $1(3.70 \%)$ & $0(0.0 \%)$ \\
\hline Grade III & $2(7.40 \%)$ & $0(0.0 \%)$ & $1(3.70 \%)$ & $0(0.0 \%)$ \\
\hline Grade IV & $0(0.0 \%)$ & $0(0.0 \%)$ & $0(0.0 \%)$ & $0(0.0 \%)$ \\
\hline Grade V(postoperative mortality) & $0(0.0 \%)$ & $0(0.0 \%)$ & $0(0.0 \%)$ & $0(0.0 \%)$ \\
\hline
\end{tabular}


Table IX: Treatment, therapeutic response and postoperative surgical complications in group II 13 patients (11 synchronous LMs +2 metachronous LMs).

\begin{tabular}{|c|c|c|c|c|}
\hline Variables & Baseline evaluation & At 3 months & At 6 months & At 9 months \\
\hline \multicolumn{5}{|l|}{ Surgical Treatment } \\
\hline \multicolumn{5}{|l|}{ Primary tumor } \\
\hline curative intent resection $^{a}$ & $11(84.61 \%)$ & n.a. & n.a. & n.a. \\
\hline palliative interventions $^{b}$ & $0(0.0 \%)$ & n.a. & n.a. & n.a. \\
\hline previous resection $^{c}$ & $2(15.38 \%)$ & n.a. & n.a. & n.a. \\
\hline \multicolumn{5}{|l|}{ Liver metastases } \\
\hline minor resection $^{d}$ & $0(0.0 \%)$ & $0(0.0 \%)$ & $0(0.0 \%)$ & $0(0.0 \%)$ \\
\hline major resection $^{e}$ & $0(0.0 \%)$ & $0(0.0 \%)$ & $3(23.07 \%)$ & $0(0.0 \%)$ \\
\hline positive resection margins & n.a. & n.a. & $0(0.0 \%)$ & n.a. \\
\hline Complementary interventions ${ }^{\dagger}$ & $8(61.53 \%)$ & $0(0.0 \%)$ & $1(7.69 \%)$ & $2(15.38 \%)$ \\
\hline Associated interventions ${ }^{g}$ & $2(15.38 \%)$ & $0(0.0 \%)$ & $0(0.0 \%)$ & $0(0.0 \%)$ \\
\hline Unoperated patients ${ }^{h}$ & $0(0.0 \%)$ & $0(0.0 \%)$ & $0(0.0 \%)$ & $0(0.0 \%)$ \\
\hline \multicolumn{5}{|l|}{ Oncological Treatment } \\
\hline neoadjuvant chemotherapy & $11(84.61 \%)$ & $6(46.15 \%)$ & $0(0.0 \%)$ & $0(0.0 \%)$ \\
\hline adjuvant chemotherapyj & $0(0.0 \%)$ & $0(0.0 \%)$ & $3(23.07 \%)$ & $3(23.07 \%)$ \\
\hline induction chemotherapy ${ }^{k}$ & $2(15.38 \%)$ & $6(46.15 \%)$ & $3(23.07 \%)$ & $0(0.0 \%)$ \\
\hline palliative chemotherapy & $0(0.0 \%)$ & $1(7.69 \%)$ & $7(53.84 \%)$ & $10(76.92 \%)$ \\
\hline molecular therapy' & $3(23.07 \%)$ & $3(23.07 \%)$ & $3(23.07 \%)$ & $3(23.07 \%)$ \\
\hline \multicolumn{5}{|l|}{ Treatment Response } \\
\hline \multicolumn{5}{|l|}{ RECIST $^{m}$} \\
\hline partial response $^{n}$ & n.a. & $0(0.0 \%)$ & $2(15.38 \%)$ & $0(0.0 \%)$ \\
\hline complete reponse $^{\circ}$ & n.a. & $0(0.0 \%)$ & $0(0.0 \%)$ & $0(0.0 \%)$ \\
\hline stable disease & n.a. & $6(46.15 \%)$ & $3(23.07 \%)$ & $5(38.46 \%)$ \\
\hline progressive disease & n.a. & $7(53.84 \%)$ & $8(61.53 \%)$ & $8(61.53 \%)$ \\
\hline \multicolumn{5}{|l|}{ Site of tumor progression } \\
\hline primary tumor ${ }^{p}$ & n.a. & $0(0.0 \%)$ & $1(7.69 \%)$ & $1(7.69 \%)$ \\
\hline Liver $^{r}$ & n.a. & $6(46.15 \%)$ & $6(46.15 \%)$ & $5(38.46 \%)$ \\
\hline Extrahepatics & n.a. & $1(7.69 \%)$ & $1(7.69 \%)$ & $1(7.69 \%)$ \\
\hline Mixed & n.a. & $0(0.0 \%)$ & $0(0.0 \%)$ & $1(7.69 \%)$ \\
\hline Non-surgical mortality & $0(0.0 \%)$ & $0(0.0 \%)$ & $0(0.0 \%)$ & $0(0.0 \%)$ \\
\hline \multicolumn{5}{|c|}{ Postoperative Surgical Complications (Clavien - Dindo classification) } \\
\hline Grade I & $4(30.76 \%)$ & $0(0.0 \%)$ & $2(15.38 \%)$ & $0(0.0 \%)$ \\
\hline
\end{tabular}

Table X: Treatment, therapeutic response and postoperative surgical complications in group III 15 patients (13 synchronous LMs +2 metachronous LMs).

\begin{tabular}{|c|c|c|c|c|}
\hline Variables & Baseline evaluation & At 3 months & At 6 months & At 9 months \\
\hline \multicolumn{5}{|l|}{ Surgical Treatment } \\
\hline \multicolumn{5}{|l|}{ Primary Tumor } \\
\hline curative intent resection $^{\mathrm{a}}$ & $13(86.66 \%)$ & n.a. & n.a. & n.a. \\
\hline palliative interventions ${ }^{b}$ & $0(0.0 \%)$ & n.a. & n.a. & n.a. \\
\hline previous resection $^{c}$ & $2(13.33 \%)$ & n.a. & n.a. & n.a. \\
\hline \multicolumn{5}{|l|}{ Liver Metastases } \\
\hline minor resection ${ }^{d}$ & $0(0.0 \%)$ & $0(0.0 \%)$ & $0(0.0 \%)$ & $0(0.0 \%)$ \\
\hline major resection ${ }^{e}$ & $0(0.0 \%)$ & $0(0.0 \%)$ & $0(0.0 \%)$ & $4(26.66 \%)$ \\
\hline positive resection margins & n.a. & n.a. & n.a. & $0(0.0 \%)$ \\
\hline Complementary interventions ${ }^{f}$ & $12(80 \%)$ & $5(33.33 \%)$ & $0(0.0 \%)$ & $4(26.66 \%)$ \\
\hline Associated interventions $^{g}$ & $2(13.33 \%)$ & $0(0.0 \%)$ & $0(0.0 \%)$ & $1(6.66 \%)$ \\
\hline Unoperated patients $^{\mathrm{h}}$ & $0(0.0 \%)$ & $0(0.0 \%)$ & $0(0.0 \%)$ & $0(0.0 \%)$ \\
\hline \multicolumn{5}{|l|}{ Oncological Treatment } \\
\hline neoadjuvant chemotherapyi & $0(0.0 \%)$ & $0(0.0 \%)$ & $0(0.0 \%)$ & $0(0.0 \%)$ \\
\hline adjuvant chemotherapy ${ }^{j}$ & $0(0.0 \%)$ & $0(0.0 \%)$ & $0(0.0 \%)$ & $4(26.66 \%)$ \\
\hline induction chemotherapyk & $14(93.33 \%)$ & $10(66.66 \%)$ & $7(46.66 \%)$ & $2(13.33 \%)$ \\
\hline palliative chemotherapy & $0(0.0 \%)$ & $4(26.66 \%)$ & $7(46.66 \%)$ & $8(53.33 \%)$ \\
\hline molecular therapy' & $4(26.66 \%)$ & $5(33.33 \%)$ & $5(33.33 \%)$ & $5(33.33 \%)$ \\
\hline \multicolumn{5}{|l|}{ Treatment Response } \\
\hline \multicolumn{5}{|l|}{$\mathrm{RECIST}^{\mathrm{m}}$} \\
\hline partial response $^{n}$ & n.a. & $1(6.66 \%)$ & $1(6.66 \%)$ & $0(0.0 \%)$ \\
\hline complete reponse $^{\circ}$ & n.a. & $0(0.0 \%)$ & $0(0.0 \%)$ & $0(0.0 \%)$ \\
\hline stable disease & n.a. & $9(60 \%)$ & $6(40 \%)$ & $6(40 \%)$ \\
\hline progressive disease & n.a. & $4(26.66 \%)$ & $7(46.66 \%)$ & $8(53.33 \%)$ \\
\hline
\end{tabular}




\begin{tabular}{|c|c|c|c|c|}
\hline \multicolumn{5}{|l|}{ Site of tumor progression } \\
\hline primary tumor $^{p}$ & n.a. & $1(6.66 \%)$ & $1(6.66 \%)$ & $1(6.66 \%)$ \\
\hline Liver $^{r}$ & n.a. & $1(6.66 \%)$ & $3(20 \%)$ & $4(26.66 \%)$ \\
\hline Extrahepatics & n.a. & $2(13.33 \%)$ & $1(6.66 \%)$ & $1(6.66 \%)$ \\
\hline Mixed & n.a. & $0(0.0 \%)$ & $2(13.33 \%)$ & $2(13.33 \%)$ \\
\hline Non-surgical mortality & $0(0.0 \%)$ & $0(0.0 \%)$ & $0(0.0 \%)$ & $0(0.0 \%)$ \\
\hline \multicolumn{5}{|c|}{ Postoperative Surgical Complications (Clavien - Dindo classification) } \\
\hline Grade I & $4(26.66 \%)$ & $0(0.0 \%)$ & $0(0.0 \%)$ & $2(13.33 \%)$ \\
\hline Grade II & $4(26.66 \%)$ & $0(0.0 \%)$ & $0(0.0 \%)$ & $0(0.0 \%)$ \\
\hline Grade III & $2(13.33 \%)$ & $0(0.0 \%)$ & $0(0.0 \%)$ & $2(13.33 \%)$ \\
\hline Grade IV & $2(13.33 \%)$ & $0(0.0 \%)$ & $0(0.0 \%)$ & $1(6.66 \%)$ \\
\hline Grade V(postoperative mortality) & $1(6.66 \%)$ & $0(0.0 \%)$ & $0(0.0 \%)$ & $0(0.0 \%)$ \\
\hline
\end{tabular}

without positive resection margins on morpho-pathological evaluation; only 4 of the 7 patients received molecular therapy;

There was no complete response at 9 months;

A partial response to treatment was obtained in 8 patients $(7.55 \%)$, only 2 of them (1.88\%) in groups II and III; no partial or complete response was obtained in any group IV patients;

Signs of progressive disease were found in 45 patients (42.45\%), none in group I;

There were 12 recorded deaths (11.32\%) out of which 9 were nonsurgery related $(8.49 \%)$ and $3(2.83 \%)$ post-surgery; the latter resulted from septic complications after primary tumor approach (colostomy necrosis, anastomotic fistula, pelvic abscess); there has been no recorded death following the liver resections.

Although the patients characteristics, as well as the primary tumor's and LMs' characteristics were analyzed in all 4 study groups, relevant to this study were only groups II (possible resectability) and III (susceptible resectability), whose therapeutic and post-therapeutic characteristics are shown in Tables 9 and 10.

While combining the results for groups II and III, the resulting rate of conversion to resectability (CRR) is $7 / 28$ patients (25\%) after 9 months. The absolute disease progression time interval (ADPT) is 3 months for 11 patients, 6 months for 4 patients and 9 months for 1 patient. The absolute disease progression rate (ADPR) is the $5 / 28$ patients $(17.85 \%)$ at 3 months, of $14 / 28$ patients (50\%) at 6 months and $18 / 28$ patients $(64.28 \%)$ at 9 months.

\section{Discussions}

The identification of a scientific protocol based on standard diagnosis and treatment criteria and particularly the standard treatment response assessment criteria is the goal for any multidisciplinary team involved in the treatment and management of patients with CRLM.

Two decades ago, patients with unresectable liver metastases were treated with systemic chemotherapy, no other therapeutic options being considered even when there was a good response to chemotherapy. Currently, the periodic reassessment of patients receiving adjuvant treatment and the extended indications for liver resection lead to improved outcomes in terms of survival [5]. Hence it can be concluded that all goals of therapeutic strategies converge on increasing the proportion of patients that may benefit from hepatic resection. The use of "adjuvant" techniques can determine an increase in the rate of conversion to resectability of liver metastases by liver morphological changes reflected by:

Decrease in volume of liver metastases

Increase in volume of healthy liver parenchyma

A consensus conference in 2006 defined three criteria to be observed in a liver resection, regardless of its magnitude [16]:
- Complete R0 resection with a safety margin $\geq 1 \mathrm{~cm}$ (gold standard), but a safety margin $<1 \mathrm{~cm}$ is not a contraindication for resection;

- Preservation of at least 2 adjacent segments with an adequate vascular inflow and outflow (portal and arterial blood supply, venous drainage) and biliary drainage;

- Adequate volume of the remaining liver (more than $20 \%$ for a healthy liver).

In this study, the criteria for assigning patients to a study group overlap some liver resectability classes. These criteria are based exclusively on imaging results without taking into account the comorbidities and surgical risk.

The statistically significant differences between the study groups on one hand and associated conditions (Charlson Comorbidity Index, $\mathrm{p}=0.0002$ ) and anesthetic risk (ASA score) on the other hand, show that the group distribution of patients is directly correlated with life expectancy.

Statistical interpretation (Fisher test) of the data obtained after the analysis of the pathology results for the primary tumor, as an important prognostic factor, indicates significant study group variations in terms of the degree of primary tumor local invasion $\mathrm{T}(\mathrm{p}=0.0031)$. Thus it can be stated that patients with primary tumors exceeding the visceral peritoneum and or invading neighboring organs (T4a,b) have or will develop forms of local or distant recurrences (hepatic and extrahepatic) generally categorized as unresectable. Statistically significant results $(p<0.0001)$ were also obtained for the G-degree of tumor differentiation. Based on these data it can be stated that the degree of tumor differentiation has an influence on the development of local or distant recurrence (hepatic and extrahepatic); poorly differentiated, aggressive tumors, will develop hepatic or extrahepatic metastases sooner, categorized as unresectable. In contrast, no significant variations were found in the number of invaded lymph nodes, $\mathrm{N}$, $(\mathrm{p}=0.2473)$, so this study could not demonstrate a correlation between the number of lymph nodes invaded and the resectability class of liver metastases.

The analysis and interpretation of the results, obtained by statistical processing of the data related to tumor marker levels (CEA and CA199), showed no statistically significant differences between the study groups. Although visually the data indicate an increasing trend of CEA levels in relation to the study groups, the ANOVA test showed statistically insignificant study group differences $(F=0.851, p=0.471)$, accounted for by the high variance in CEA levels within the study groups. For the CA19-9 marker, the ANOVA test also indicates, at a significance level of 0.05 , that the differences between study groups are not statistically significant $(\mathrm{F}=2.037, \mathrm{p}=0.117)$. This may be due to the high variation of tumor markers in small study groups. CA19-9 marker had an unexpected "behavior". Thus in group III its levels were lower than in group II. This marker being a derivative of the Lewis blood group 
Table XI: Treatment, therapeutic response and postoperative surgical complications in group IV 51 patients ( 31 synchronous LMs +20 metachronous LMs).

\begin{tabular}{|c|c|c|c|c|}
\hline Variables & Baseline evaluation & At 3 months & At 6 months & At 9 months \\
\hline \multicolumn{5}{|l|}{ SURGICAL TREATMENT } \\
\hline \multicolumn{5}{|l|}{ Primary tumor } \\
\hline curative intent resection $^{a}$ & $12(23.52 \%)$ & n.a. & n.a. & n.a. \\
\hline palliative interventions $^{b}$ & $14(27.45 \%)$ & n.a. & n.a. & n.a. \\
\hline previous resection $^{c}$ & $20(39.21 \%)$ & n.a. & n.a. & n.a. \\
\hline \multicolumn{5}{|l|}{ Liver metastases } \\
\hline minor resection $^{d}$ & $0(0.0 \%)$ & $0(0.0 \%)$ & $0(0.0 \%)$ & $0(0.0 \%)$ \\
\hline major resectione & $0(0.0 \%)$ & $0(0.0 \%)$ & $0(0.0 \%)$ & $0(0.0 \%)$ \\
\hline positive resection margins & n.a. & n.a. & n.a. & n.a. \\
\hline Complementary interventions ${ }^{f}$ & $9(17.64 \%)$ & $0(0.0 \%)$ & $0(0.0 \%)$ & $0(0.0 \%)$ \\
\hline Associated interventions ${ }^{9}$ & $11(21.56 \%)$ & $0(0.0 \%)$ & $0(0.0 \%)$ & $0(0.0 \%)$ \\
\hline Unoperated patients $^{\mathrm{h}}$ & $5(9.80 \%)$ & $5(9.80 \%)$ & $5(9.80 \%)$ & $5(9.80 \%)$ \\
\hline \multicolumn{5}{|l|}{ ONCOLOGICAL TREATMENT } \\
\hline neoadjuvant chemotherapyi & $0(0.0 \%)$ & $0(0.0 \%)$ & $0(0.0 \%)$ & $0(0.0 \%)$ \\
\hline adjuvant chemotherapyj & $0(0.0 \%)$ & $0(0.0 \%)$ & $0(0.0 \%)$ & $0(0.0 \%)$ \\
\hline induction chemotherapy ${ }^{k}$ & $0(0.0 \%)$ & $0(0.0 \%)$ & $0(0.0 \%)$ & $0(0.0 \%)$ \\
\hline palliative chemotherapy & $49(96.07 \%)$ & $49(96.07 \%)$ & $48(94.11 \%)$ & $41(80.39 \%)$ \\
\hline molecular therapy' & $16(31.37 \%)$ & $16(31.37 \%)$ & $15(29.41 \%)$ & $12(23.52 \%)$ \\
\hline \multicolumn{5}{|l|}{ TREATMENT RESPONSE } \\
\hline \multicolumn{5}{|l|}{$\mathrm{RECIST}^{\mathrm{m}}$} \\
\hline partial response $^{n}$ & n.a. & $0(0.0 \%)$ & $0(0.0 \%)$ & $0(0.0 \%)$ \\
\hline complete reponse $^{\circ}$ & n.a. & $0(0.0 \%)$ & $0(0.0 \%)$ & $0(0.0 \%)$ \\
\hline stable disease & n.a. & $22(43.13 \%)$ & $21(41.17 \%)$ & $10(19.60 \%)$ \\
\hline progressive disease & n.a. & $27(52.94 \%)$ & $27(52.94 \%)$ & $31(69.78 \%)$ \\
\hline \multicolumn{5}{|l|}{ Site of tumor progression } \\
\hline primary tumor ${ }^{p}$ & n.a. & $2(3.92 \%)$ & $2(3.92 \%)$ & $1(1.96 \%)$ \\
\hline Liver & n.a. & $3(5.88 \%)$ & $2(3.92 \%)$ & $4(7.84 \%)$ \\
\hline Extrahepatic ${ }^{s}$ & n.a. & $16(31.37 \%)$ & $15(29.41 \%)$ & $17(33.33 \%)$ \\
\hline Mixed & n.a. & $6(11.76 \%)$ & $8(15.68 \%)$ & $9(17.64 \%)$ \\
\hline Non-surgical mortality & $0(0.0 \%)$ & $0(0.0 \%)$ & $1(1.96 \%)$ & $7(13.72 \%)$ \\
\hline \multicolumn{5}{|c|}{ POSTOPERATIVE SURGICAL COMPLICATIONS (Clavien - Dindo classification) } \\
\hline Grade I & $16(31.37 \%)$ & $0(0.0 \%)$ & $0(0.0 \%)$ & $0(0.0 \%)$ \\
\hline Grade II & $17(33.33 \%)$ & $0(0.0 \%)$ & $0(0.0 \%)$ & $0(0.0 \%)$ \\
\hline Grade III & $3(5.88 \%)$ & $0(0.0 \%)$ & $0(0.0 \%)$ & $0(0.0 \%)$ \\
\hline Grade IV & $2(3.92 \%)$ & $0(0.0 \%)$ & $0(0.0 \%)$ & $0(0.0 \%)$ \\
\hline Grade V(postoperative mortality) & $2(3.92 \%)$ & $0(0.0 \%)$ & $0(0.0 \%)$ & $0(0.0 \%)$ \\
\hline
\end{tabular}

n.a. - not applicable

a - right or left colectomies, total colectomies, anterior rectal resections, abdomino-perineal rectum excisions,

Hartmann operations

b - digestive bypass, colostomy

c - for patients with metachronous LMs

$\mathrm{d}$ - segmentectomies ( $\leq 3$ liver segments), metastasectomies, "wedge resection"

e - liver resection $>3$ liver segments

$\mathrm{f}$ - locoregional lymphadenectomy (usually associated with major resections), excision of lymph node

recurrences, termoablation, portal vein ligature, port-a-cath insertion into hepatic artery, peritoneal biopsy (classic

/ laparoscopic approach) liver biopsy (classic / laparoscopic approach); here were also included the interventional

radiology techniques (portal vein embolization and hepatic artery chemoembolization)

$\mathrm{g}$ - hysterectomy, Hartmann's reversal, enterectomy, appendectomy, cholecystectomy, inguinal hernia surgical

repair, surgical repair of incisional hernia

$\mathrm{h}$ - for patients unoperated after enrollment in the research

$\mathrm{i}$ - performed in patients with resectable LMs, after resection of primary tumor, pending liver sequence

j - systemic and / or locoregional administration in all patients who underwent liver resection

$\mathrm{k}$ - administered in patients with probable or likely resectable LMs, pending surgical sequence

I - targeted monoclonal antibodies (cetuximab, bevacizumab)

m - Response Evaluation Criteria in Solid Tumors

$\mathrm{n}$ - at least a $30 \%$ decrease in the sum of diameters of target lesions

$\mathrm{o}$ - disappearance of all target lesion

$p$ - recurrence or tumor continues to progress

$r$ - number and size assessment

$\mathrm{s}$ - lung, peritoneal, retroperitoneal, ovarian, bone 
Table XII: Main criteria for therapeutic response assessment.

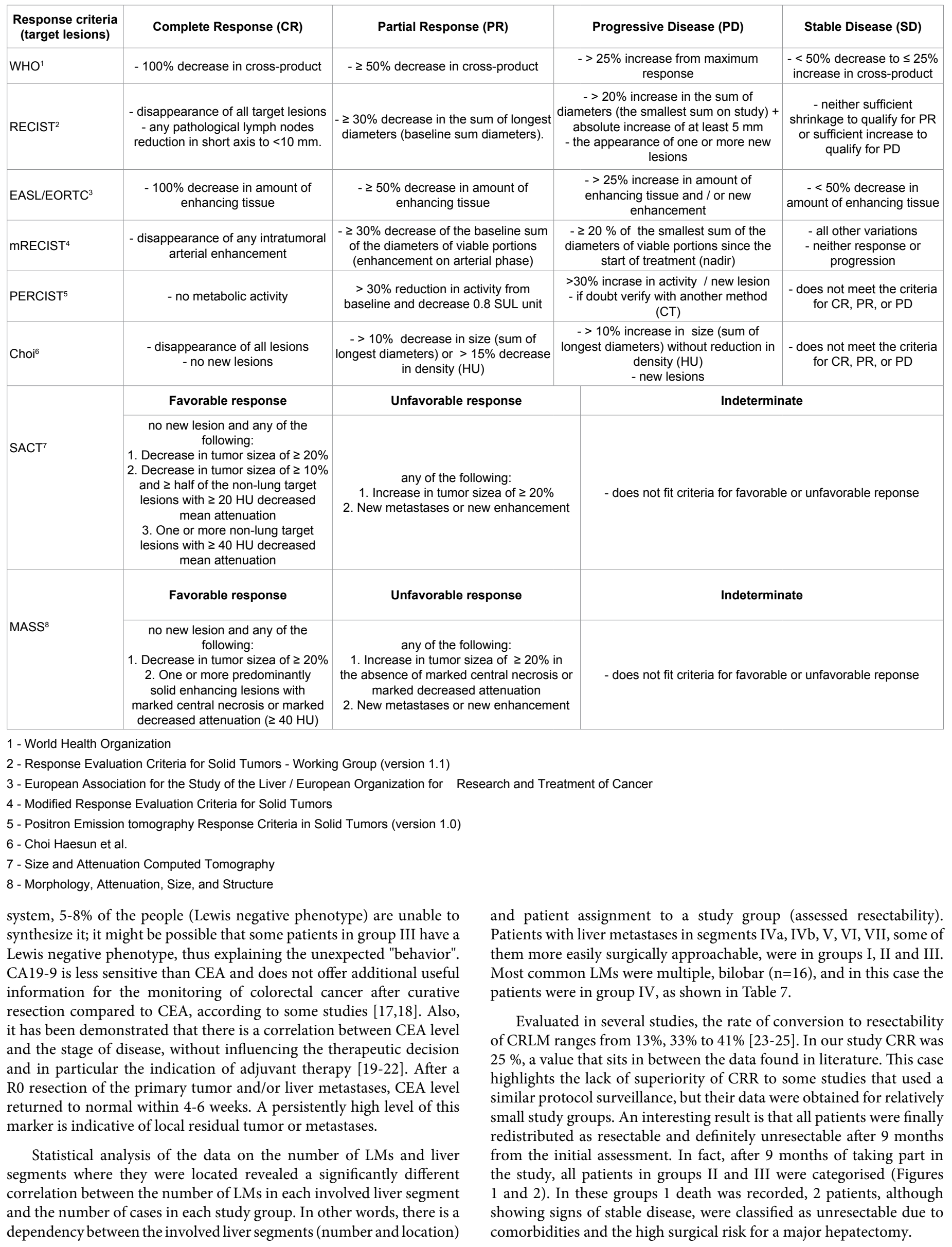


There were significant differences between the CRR even for patients under a rigorous surveillance protocol [23-25]. These differences may result from different appreciations of the indication for liver resection. The indication for liver resection is established by the surgical team, which should take into account two factors:

- General health status of the patient (comorbidities and anesthetic risk);

- Therapeutic response evaluation.

Perhaps the most important step in the surgical oncology strategy for CRLM patients is the therapeutic response evaluation (at baseline and at well-established intervals) with reconsideration of liver resection. The most widely used criteria for treatment response assessment is RECIST (Response Evaluation Criteria In Solid Tumors). These are imaging criteria and consist of initial examination prior to treatment and dynamic (baseline and follow-up) evaluation of CT/MRI images (not by chest X-ray or abdominal ultrasound) and evaluates only the size and number of target lesions without considering the morphological changes of target lesions. PET-scan ${ }^{18}$ FDG (fluorodeoxy-glucose positron emission tomography) can be used to confirm/ refute the appearance of one or more new lesions. RECIST criteria were created simplistic, arbitrary, for clinical trials studying the efficacy of chemotherapy in hepatocellular carcinoma being subsequently adopted in practice. RECIST criteria are not adapted to the mechanisms of action of angiogenesis inhibitors (anti-VEGF antibody, bevacizumab), molecular therapy used since 2004 in patients with metastatic CRC. Anti-angiogenic agents (anti-VEGF) do not destroy cancer cells and do not have a direct cytocidal effect, as conventional chemotherapeutic agents, but prevent the development of peritumoral vascular micronetwork thereby limiting tumor growth, having a cytostatic effect. The combination chemotherapy + anti-angiogenic agents appear to be an optimal anti-cancer treatment, but the classical evaluation criteria (CT/MRI) cannot capture changes in morphology. Therefore, these biological agents do not have a direct effect on tumor volume, and a simple CT / MRI scam may underestimate the response to treatment.

A short meta-analysis showed that there are numerous criteria to assess therapeutic response in oncological diseases, some of them adapted to current therapy and technology. Studies in which these criteria have proven their usefulness and contribution to survival or quality of life were designed for a specific neoplastic disease, but later applied to other neoplastic diseases. Most therapeutic response assessment criteria have been created to monitor the effectiveness of one anti-cancer agent in phase II and III studies. WHO (World Health Organization) criteria and RECIST (Response Evaluation Criteria in Solid Tumors) are mainly focused on the evaluation on anatomic tumor response and were initially used for hepatocellular carcinoma.

EASL / EORTC criteria (European Association for the Study of the Liver / European Organization for Research and Treatment of Cancer) assess tumor enhancement also in hepatocellular carcinoma. mRECIST (modified Response Evaluation Criteria for Solid tumors) criteria differ from RECIST as they measure tumor enhancement as a biomarker of tumor viability. PERCIST criteria (Positron Emission Tomography Response Criteria in Solid tumors) use a metabolic assessment of the tumor tissue rather than by recording of a decrease in anatomic size. Choi criteria described by Choi Haesun et al. for the assessment of therapeutic response in gastrointestinal stromal tumors (GIST) consider both target lesion size and its density expressed in Hounsfield units. Smith AD et al. have developed criteria for assessing the progression of liver metastases of renal origin called SACT (vfgtgrwhich were modified by the same team a year later into MASS (Morphology, Attenuation, Size, and Structure) [26-39]. Key features of therapeutic response assessment criteria are shown in Table 12.

In a study conducted by a multidisciplinary team under the direction of L. Rubbia-Brandt in 196 patients with CRLM the post-

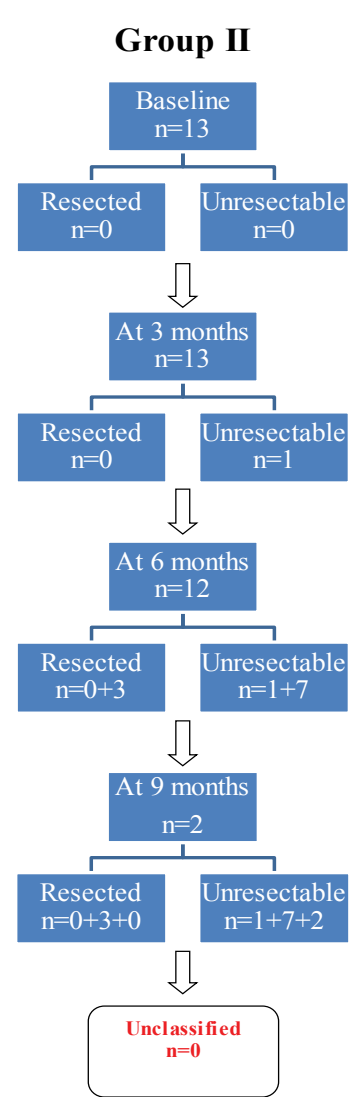

Figure 1: The pacients redistribution after 9 months of baseline evaluation (group II).

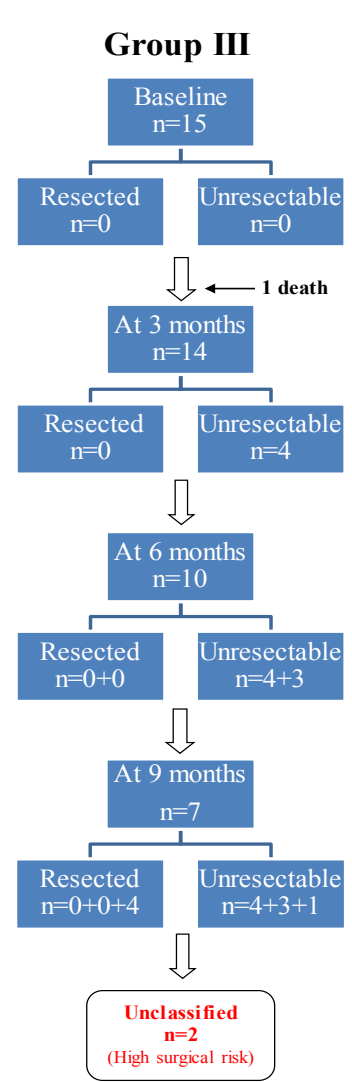

Figure 2: TThe pacients redistribution after 9 months of baseline evaluation (group III). 
terapeutic response was evaluated based on morphopathological analysis of resection specimen. A tumor regression score (TRG) was used and a correlation between this score and overall survival was found. This score identifies five levels of tumor regression and is based on the presence of residual tumor and extent of fibrosis. For CRLM, the occurrence of fibrosis is correlated with a favorable response to chemotherapy and not with the occurrence of areas of tumor necrosis [40].

A muldidisciplinary team from The University of Texas, MD Anderson Cancer Center, led by D. Ribero assessed the therapeutic response based on a morphopathological analysis of resection specimens. One hundred five patients with CRLM who received induction chemotherapy + bevacizumab $(n=62)$ and oxaliplatin / 5-FU without bevacizumab $(n=43)$ had been assessed. There was a significant decrease in the degree of tumor viability in the group treated with bevacizumab compared to the group treated solely chemotherapically $(45.3 \%$ vs. $32.9 \%)$. Moreover, they found that the therapeutic response in patients treated with bevacizumab was significantly more pronounced in lesions $\leq 4 \mathrm{~cm}$ and was independent of the duration of chemotherapy $[41,42]$.

Another multidisciplinary team from The University of Texas, MD Anderson Cancer Center, led by Yun Shin Chun, analyzed 234 liver metastases of colorectal cancer in 50 patients receiving chemotherapy and bevacizumab as first line therapy. The therapeutic response was interpreted with RECIST and based on the morphological features on DCE-CT (Dynamic Contrast Enhanced-CT): overall attenuation, tumor-liver interface, and peripheral rim of enhacement. A correlation between therapeutic response assessed by these criteria and morphopathological analysis was found. For the validation another group of 87 patients who underwent chemotherapy alone was used, finding a correlation between CT features of morphopathological response and overall survival, but not the same correlation as when RECIST was used [33].

These studies, by the used methods, suggest the superiority of morphopathological criteria in the assessment of therapeutic response. In addition to the size and number of assessed lesions, the imaging tests performed after therapy reveal structural changes of target lesion (deformation of tumor contour, areas of tumor necrosis, mucinous cell-free areas, areas of fibrosis) and peritumoral area (blood supply reduced and stopped with or without reduction in tumor size, areas of fibrosis). The use of such criteria would change the assignment of patients according to response to treatment and decision on resectability conversion with a direct impact on survival and improved quality of life. An area of peritumoral fibrosis of several millimeters could make the difference between a $\mathrm{R} 0$ and a $\mathrm{R} 1$ resection.

\section{Conclusions}

Conversion to resectability rate (CRR) is $7 / 28$ patients $(25 \%)$ after 9 months.

The absolute disease progression time interval (ADPT) is 3 months for 11 patients, 6 months for 4 patients, and 9 months for 1 patient.

The absolute disease progression rate (ADPR) is the $5 / 28$ patients (17.85\%) at 3 months, of $14 / 28$ patients (50\%) at 6 months and $18 / 28$ patients (64.28\%) at 9 months.

Rigorous surveillance of patients with CRLM according to a wellestablished scientific protocol with their integration into classes of liver resectability and control at 3 months (after 3 cycles of chemotherapy) represent the first step in onco-surgical therapeutic strategy. An improved rate of conversion to resectability could be achieved through regular assessment of treatment response based on international criteria including besides the number and size of target lesions the post-therapeutic tumor morphological changes.
Response assessment according to RECIST criteria can not confirm the resectability of CRML; according to RECIST, signs of stable disease may be an indication for liver resection in patients with possibly or susceptible resectable metastases.

Using response assessment criteria adapted to the new therapeutic and technological discoveries, will be felt in the way of communication one with another in the multidisciplinary team, and with the patient.

\section{Acknowledgement}

This study received financial support through the "Program of Excellence in multidisciplinary doctoral and postdoctoral research in chronic diseases", contract identification number: HRD / 159 / 1.5 / S / 133377. Beneficiary "Gr. T. Popa "lasi, financed from the European Social Fund Operational Programme Human Resources Development 2007-2013."

\section{Conflict of interests}

Authors have no conflict of interests to disclose.

\section{References}

1. ${ }^{* *}$ http://globocan.iarc.fr/Pages/fact_sheets_cancer.aspx

2. ***http://www.cancer.org/cancer/colonandrectumcancer/detailedguide/ colorectal-cancer-survival-rates

3. Nordlinger B, Guiguet M, Vaillant JC, Balladur P, Boudjema K, et al. (1996) Surgical resection of colorectal carcinoma metastases to the liver. A prognosting scoring sistem to improve case selection, based on 1568 patients. Association Francaise de Chirurgie. Cancer 77: 1254-1262.

4. Jaeck D, Bachellier P, Guiguet M, Boudjema K, Vaillant JC et al. (1997) Longterm survival following resection of colorectal hepatic metastases. Association Francaise de Chirurgie. Br j Surg 84: 977-980.

5. Rougier P, Milan C, Lazorthes F, Fourtanier G, Partensky C, et al. (1995) Prospective study of prognostic factors in patients with unresected hepatic metastases from colorectal cancer. Fondation Française de Cancérologie Digestive. Br J Surg 82: 1397-1400.

6. Fong Y, Fortner J, Sun RL, Brennan MF, Blumgart LH (1999) Clinical score for predicting recurrence after hepatic resection for metastatic colorectal cancer: analysis of 1001 consecutive cases. Ann Surg 230: 309-318 Discussion : 318321.

7. Adam R, Aloia T, Figueras J, Capussotti L, Poston G, et al. (2006) LiverMetSurvey: analysis of clinicopathologic factors associated With the efficacy of preoperative chemotherapy in 2122 patients with colorectal liver metastases. J Clin Oncol 24: abstract 3521.

8. Chun YS, Vauthey JN (2007) Extending the frontiers of resecabilyty in advsnced colo-rectal cancer. Eur J Surg Oncol 33: S52-58.

9. Goere D, Elias D, Pocard M (2007) Actualites dans le traitement chirurgical des metastases hepatiques. Hepato-Gastro 14: 38-44. [article in French]

10. Nordlinger B, Sorbye H, Glimelius B, Poston GJ, Schlag PM, et al. (2008) Perioperative chemotherapy with FOL-FOX 4 and surgery versus surgery alone for resectable liver metastases from colorectal cancer (EORTC intergrup trial 40983): a randomised controlled trial. Lancet 371: 1007-1018.

11. RenehanAG, Egger M, SaundersMP, O'Dwyer ST (2002) Impact on survival of intensive follow up after curative resection for colorectal cancer: systematic review and meta-analysis of randomised trials. BMJ 324: 813.

12. Child PW, Yan TD, Perera DS, Morris DL (2005) Surveillance-detected hepatic metastases from colorectal cancer had a survival advantage in seven-year follow-up. Dis Colon Rectum 48:744-748.

13. Jaeck D, Bachellier P, Guiguet M, Boudjema K, Vaillant JC, et al (1997) Long term survival following resection of colorectal hepatic metastases. Association Francaise de Chirurgie. Br j Surg 84: 977-980.

14. Bismuth $H$, Adam R, Vibert É (2008) Influence of chemotherapy in the treatment of colorectal liver metastases. e-Mémoires de l'Académie Nationale de Chirurgie 7: 20-25. [article in French]

15. ***htp://www.eortc.be/Recist/documents/RECISTGuidelines.pdf

16. Charnsangavej C, Clary B, FongY, Grothey A, Pawlik TM, et al. (2006) Selection of pacients for resection of hepatic colorectal metastases: expert consensus statement. Ann Surg Oncol 13: 1261-1268.

17. McCall JL, Black RB, Rich CA, Harvey JR, Baker RA, et al. (1994) The value of serum carcinoembryonic antigen in predicting recurrent disease following curative resection of colorectal cancer. Dis Colon Rectum 37: 875-881. 
18. Moertel CG, Fleming TR, MacDonald JS, Haller DG, Laurie JA, et al. (1993) An elevation of the carcinoembryonic antigen (CEA) test for monitoring patients with resected côlon cancer. JAMA 270: 943-947.

19. Carriquiry LA, Pineyro A (1999) Should carcino embryonic antigen be use in the management of patients with colorectal cancer? Dis Colon Rectum 4: 921-929.

20. Chapman MA, Buckley D, Henson DB, Armitage NC (1998) Preoperative carcinoembryonic antigen is related to tumour stage and long-term survival in colorectal cancer. Br JCancer 78: 1346-1349.

21. Conférence de consensus (1998) Prévention, dépistage et prise en charge des cancers du côlon. Textes des experts et du groupe bibliographique. Conclusions et recommandations du jury. Paris 29-30 janvier 1998. Gastroentérol Clin Bio 22 ( $n^{\circ} 3$ bis)

22. Conroy T, Adenis A (1998) Standards, options et recommandations pour la surveillance après traitement d'un cancer du côlon. Bull Cancer 85: 152-159.

23. Adam R, DelvartV, Pascal G, Valeanu A, Castaing D, et al (2004) Rescue surgery for unresectable colorectal liver metastases downstaged by chemotherapy: a model to predict long-term survival. Ann Surg 240: 644-58.

24. Pozzo C, Basso M, CassanoA, Quirino M, Schinzari G, et al. (2004) Neoadjuvan treatment of unresectable liver disease with irinotecan and 5-fluorouracil plus folinic acid in colorectal cancer patients. Ann Oncol 15:933-939.

25. Blazer DG 3rd, Kishi Y, Maru DM Kopetz S, Chun YS, et al. (2008) Pathologic response to preoperative chemotherapy: a new outcome end point after resection of hepatic colorectal metastases. J Clin Oncol 26: 5344-5351.

26. Weng Z, Ertle J, Zheng S, Lauenstein T, Mueller S, et al. (2013) Choi criteria are superior in evaluating tumor response in patients treated with transarterial radioembolization for hepatocellular carcinoma. Oncol Lett 6: 1707-1712.

27. Therasse P, Arbuck SG, Eisenhauer EA, Wanders J, Kaplan RS, et al. (2000) New guidelines to evaluate the response to treatment in solid tumors. European Organization for Research and Treatment of Cancer, National Cancer Institute of the United States, National Cancer Institute of Canada. J Natl Cancer Ins 92: $205-216$.

28. Choi H, Charnsangavej C, Faria SC, Macapinlac HA, Burgess MA et al. (2007) Correlation of computed tomography and positron emission tomography in patients with metastatic gastrointestinal stromal tumor treated at a single institution with imatinib mesylate: proposal of new computed tomography response criteria. J Clin Oncol 25: 1753-1759.

29. Skougaard K, Johannesen HH, Nielsen D, Schou JV, Jensen BV, et al. (2014) CT versus FDG-PET/CT response evaluation in patients with metastatic colorectal cancer treated with irinotecan and cetuximab. Cancer Med 3: 1294 1301.

30. Chun YS, Vauthey JN, Boonsirikamchai P, Maru DM, Kopetz S, et al. (2009) Association of computed tomography morphologic criteria with pathologic response and survival in patients treated with bevacizumab for colorectal liver metastases. JAMA 302: 2338-2344.
31. Husband JE, Schwartz LH, Spencer J, Ollivier L, King DM, et al. (2004) Evaluation of the response to treatment of solid tumours-a consensus statement of the International Cancer Imaging Society. Br J Cancer 90: 22562260

32. Marcus CD, Ladam-Marcus V, Cucu C, Bouché O, Lucas L, et al. (2009) Imaging techniques to evaluate the response to treatment in oncology:Current standards and perspectives. Crit Rev Oncol Hematol 72: 217-238.

33. Smith AD, Lieber ML, Shah SN (2010) Assessing tumor response and detecting recurrence in metastatic renal cell carcinoma on targeted therapy: importance of size and attenua-tion on contrast-enhanced CT. AJR Am J Roentgenol 194:157-165.

34. Smith AD, Shah SN, Rini BI, Lieber ML, Remer EM (2010) Morphology attenuation, size, and structure (MASS) criteria: assessingresponse and predicting clinical outcome in metastatic renalcell carcinoma on antiangiogenic targeted therapy. AJR Am JRoentgenol 194: 1470-1478.

35. Fournier L, Ammari S, Thiam R, Cuénod CA Cuénod (2014) Imaging criteria for assessing tumour response: RECIST, mRECIST, Cheson. Diagn Interv Imaging 95: 689-703.

36. Lencioni R, Llovet JM (2010) Modified RECIST (mRECIST) assessment for hepatocellular carcinoma. Semin Liver Dis 30: 52-60.

37. Cheson BD, Horning SJ, Coiffier B, Shipp MA, Fisher RI, et al. (1999) Report of an international workshop to standardizeresponse criteria for non-Hodgkin's lymphomas. $\mathrm{NCl}$ Spon-sored International Working Group. J Clin Oncol 17: 1244.

38. Young H, Baum R, Cremerius U, Herholz K, Hoekstra O, et al. (1999) Measurement of clinical and subclinical tumour response using [18F] fluorodeoxyglucose and positron emission tomography: review and 1999 EORTC recommendations. European Organization for Research and Treatment of Cancer (EORTC) PET Study Group. Eur J Cancer 35: 1773-1782.

39. Wahl RL, Jacene H, Kasamon Y, Lodge MA (2009) From RECIST to PERCIST: evolving considerations for PET response criteria in solid tumors $\mathrm{J}$ Nucl Med 50:122S-150S.

40. Rubbia-Brandt L, Giostra E, Brezault C, Roth AD, Andres A. et al. (2007) Importance of histological tumor response assessment in predicting the outcome in patients with colorectal liver metastases treated with neo-adjuvan chemoterapy followed by liver surgery. ANN Oncol 18: 299-304.

41. Ribero D, Wang H, Donadon M, Zorzi D, Thomas MB, et al. (2007) Bevacizumab improve pathologic response and protects against hepatic injury in pacients treated with oxaliplatin-based chemotherapy for colorectal liver metastases. Cancer 110: 2761-2767.

42. Alberts SR, Donohue JH, Mahoney MR, Horvath WL, Sternfeld SR, et al. (2003) Liver resection after 5-fluorouracil, leucovorin and oxaliplatin for patients with metastatic colorectal cancer limited to the liver: A North Central CancerTreatment Group phase II study. ProcAm Soc Clint Oncol 21: 263. 